\title{
EXACERBATION OF ACETIC ACID ULCER INDUCED BY NON-STEROIDAL ANTI-INFLAMMATORY DRUGS IN RATS
}

\author{
Hiroshi TANAKA, Katsuichi SHUTO and Nobuhiro NAKAMIZO \\ Pharmaceuticals Researci: Laboratory, Kyowa Hakko Kogyo Co., Ltd., \\ 1188 Nagaizum-cho, Sunto-gun, Shizuoka 411, Japan
}

Accepted December 9, 1982

\begin{abstract}
The influences of non-steroidal anti-inflammatory crugs (NSAID) on acetic acid ulcer were examined in rats. NSAID used in this study were aspirin (ASP, $200 \mathrm{mg} /$ $\mathrm{kg}$ ), indomethacin (IND, $2 \mathrm{mg} / \mathrm{kg}$ ) and phenvioutazone (PHE, $100 \mathrm{mg} / \mathrm{kg}$ ). These NSAID were administered consecutively for 5 days once a day at the early stage of the ulcer. Eleven days after the ulceration, suppression of the healing was observed in rats treated with all of the NSAID. In the rats treated with either ASP or NDD, a delay of healing was observed not only 11 days after ulceration. but also 16 days after ulceration. The ulcer index in rats treated with either ASP or IND 16 days after ulceration was greater than that at 11 days after ulceration. Further studies were performed regarding the progressive change of mucosal hexosamine content, gastric secretion and gastric emptying during the realing process of the ulcer. It was found that the increase of hexosamine plays an important role in the realing of the ulcer and that a durable fall in hexosamine content was related to the remarkable exacerbation of ulcer induced by either ASP or IND. Hypersecretion, back diffusion of hydrogen ion or a delay of gastric emptying cannot be regarded as a cause of the exacerbation of the ulcer.
\end{abstract}

It is well known that non-steroidal anti inflammatury drugs (NSAID) produce gastric damage in humans as woll as in experimental animals $(1-5)$. We have reported that $N S A I D$ produced an exacerbation of acetic acid uicer in rats and the treatment with $\mathrm{N}$-acetyl-Lglutamine aluminum complox (KW-110), an antiulcer drug (1.6-11) excellently prevented the exacerbation of the ulcer (1). The present stuoy was undertaken to observe the progressive change of the ulcer index ir order to study the pathogenetic factors concerned with exacerbation of the ulcer induced by NSAID. The progressive change in the mucosal hexosamine content in the ulcerated area, gastric secretion ard gastric emptying during the healing process of the ulcer were studied in rats.

\section{Materials and Methods}

Male Donryu stain rats, weighing 190-
$200 \mathrm{~g}$. were used in this study.

Effects of NSAID on acetic acid ulcer: Under ether anesthesia, $0.025 \mathrm{ml}$ of acetic acid $(20 \%)$ were injected into the submucosal layer of the glandular stomach. according to the method of Takagi et al. (12). NSAID were orally given for 5 days from the next day following ulcer formation. The animals were killed to determine the ulcer index 6.11 or 16 days after ulcer formation. Each stomach was cut along the greater curvatura, and the ulcer index was observed. The longitudinal and abscissal lengths of the ulcer area were measured under a magnifying glass $(\times 10)$, and the multiplication product of thesc two quantities was designated as the ulcer index ( $\left.\mathrm{mm}^{2}\right)$.

Progressive change of mucosal hexosamine in the ulcerated area: A portion of the animals was used to measure the mucosal hexosamine ir the surroundings of the vilcer area at 6,11 
or 16 days after ulceration. The contents of hexosamine were measured by the method used previously (13). Each stomach was dehydrated and defatted with ethanol. acetone and ether and then dried under reduced pressure. Approx. $20 \mathrm{mg}$ of the dried tissue was determined by Masamune's method (14).

Progressive change of gastric secretion in rats with ulcer: The gastric secretion was studied in the pylorus-ligated rats. The animals were starved for $48 \mathrm{hr}$ and were provided with free access to water during starvation. The gastric juice was collected $4 \mathrm{hr}$ after the pylorus-ligation. The gastric juice was centrifuged and titrated for acidity to $\mathrm{pH}$ 7.4 with $0.05 \mathrm{~N} \mathrm{NaOH}$ using a $\mathrm{pH}$ meter. The concentration of sodium ion was measured by flame photometry. The peptic activity was measured by Anson's method (15) and represented as $L$-tyrosine content $(\mathrm{mg})$.

Progressive change of gastric emptying in rats with ulcer: The gastric emptying was measured according to the method of Bobalik et al. (16). The rats deprived of food but allowed water for $17 \mathrm{hr}$ were used. A 1\% Evan's blue solution was given orally at $1 \mathrm{ml} /$ rat. Thirty min after the administration of the dye solution, the gastric content was collected in a test tube containing $50 \mathrm{ml}$ of distilled water with a few drops of $10 \mathrm{~N} \mathrm{KOH}$ solution. The mixture was vigorously shaken and diluted 3 times by distilled water. The optical density at $450 \mathrm{~m} / 2$ of the mixture was then measurod.

Experiments in rats without ulcer: In nonulcerated rats, the influences of one shot of NSAID on both gastric secretion and gastric emptying were studied. The gastric secretion was tested in pylorus-ligated rats. NSAID was orally administered immediately after the pylorus-ligation. The gastric juice was analyzed by the method described above. Gastric emptying was measured in nonulcerated rats to which the dye solution was given 30 min after the dose of NSAID. After 30 min, the gastric content was collected to measure the dye concentration. Gastric contraction was observed with a force transducer (Star Medical, Japan) in animals anesthetized by the intraperitoneal administration of urethane at $1 \mathrm{~g} / \mathrm{kg}$. The transducer was placed on the antrum of the stomach to primarily record the contraction of the circular muscle.

Drugs: NSAID used in this study were aspirin (ASP. Sanko Selyaku), indomethacin (IND, Sigma) and phenylbutazone (PHE, Sigma). The drugs were suspended in $0.3 \%$ carboxy methyl cellulose (CMC) solution and were administered orally at a volume of $1 \mathrm{ml} /$ animal.

Statistical analysis: The differences were determined by the Student's t-test for unpaired values. A $P$ value of less than 0.05 was considered to be significant.

\section{Results}

Progressive change in ulcer index: In the control groups, the ulcer index 11 days after ulcer formation was one fourth of that 6 days after ulceration. The indices in the rats to which ASP, IND or PHE was administered were significantly high when compared with the control group 11 days after ulceration $(P<0.05)$. Either index of ASP or IND showed a significantly greater value than that of the group 16 days after ulceration $(P<0.01)$. Each value 16 days after ulceration was greater than that in the animals treated with the respective NSAID 11 days after ulceration. In the animals treated with PHE, the ulcer index 16 days after ulceration was lower than that 11 days after ulceration (Fig. 1).

Progressive change of mucosal hexosamine in the ulcerated area: Six days after ulceration, a highly significant increase in hexosamine content was shown in the control group with ulcerated rats when compared with the 


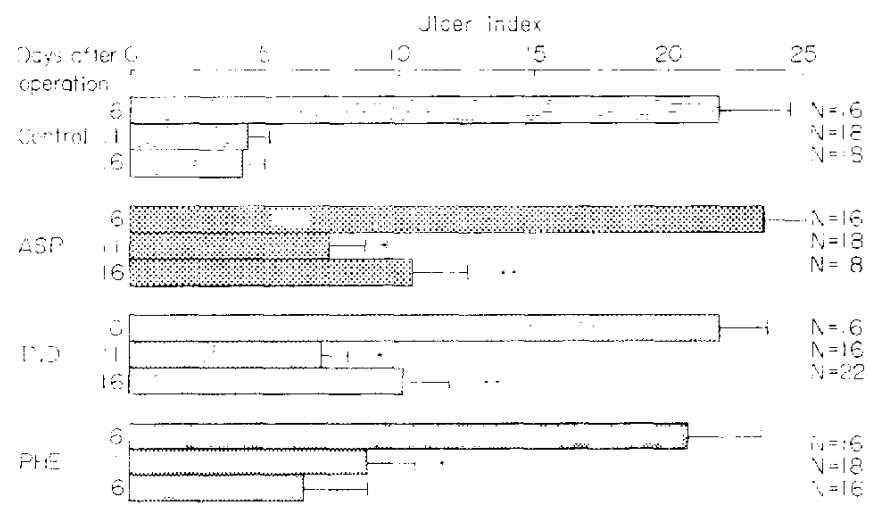

Fig. 1. Progressive change of ulcey index in rats with acetic acid uicer by NSAID. NSAID was orally administered consecutively for 5 days from the next day following ulcer formation. Control: Carboxy methyl cellulose $(0.3 \%)$ was orally administered once daily at a volume of $1 \mathrm{ml} / \mathrm{rat}$. ASP: Aspirin was administered once daily at a dose of $200 \mathrm{mg} / \mathrm{kg}$-day. IND: Indomethacin was administered once daily at a dose of $2 \mathrm{mg} / \mathrm{kg}$-day. PHE: Phenylbutazone was administered once daily at a dose of $200 \mathrm{mg} / \mathrm{kg}-$ day. Each value is the mean, and the horizontal bars represent the S.E. of the moan. The statistical significance of the difference from the control group is * $P<0.05$ or ${ }^{*} P<0.01$.

rats before ulcer formation ( $P<0.001$ ). Eleven days after ulceration, the hexosamine level in the control group became the same as the level before ulceration. In ASP-treated rats. a significantly low level of hexosamine when compared with the ulcerated control group was observed either 6 days after ulceration or 11 days after uiceration. Either day after ulceration. IND-treated rats showed a considerably lower level of hexosamine. Eleven days after ulceration, elther ASP or INDtreated rats showed a significantly lower level of hexosamine when compared with the rats before ulcer formation $(P<0.01, P<0.05$, respectively). Additionally, the level 6 days after ulceration was markedly lower than that in the ulcerated rats $(P<0.001)$. PHE caused a significantly lower level of hexosamine 6 days after ulceration, although the level on either 11 days or 16 days after ulceration was the same as that in the ulcerated control group (Fig. 2).

Progressive change of gastric secretion in pylorus-ligated rats with ulcer: In rats treated with either IND or PHE, the volume of gastric juice significantly decreased when compared with the control group (fig. 3). Six days after
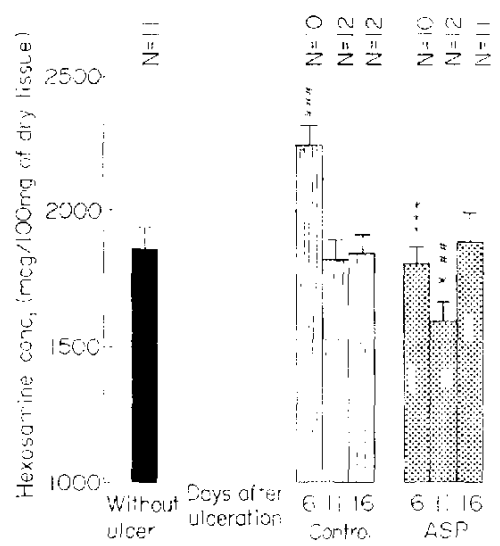

20

Fig. 2. Progressive change of mucosal hexosamine content in the ulceratod area of rat stomachs with acetic acid ulcer by NSAID. NSAID was administered in the same manner as that described ir Fig. 1. Each value is the mean, and the vertical bars represent the S.E. of the mean. The statistical significance of the difference is $\$ \$ P<0.001$, $\$ P<0.01$, or $\$ P<0.05 \mathrm{Vs}$. the value of non-ulcerated rats; ${ }^{* *} P<0.001$. ${ }^{*} P<0.01$. or $* P<0.05$ vs. the control group on the respective day.

ulceration, all of the ulcerated groups, independently of the administration of NSAID. showed significantly decreased acid output when compared with non-ulcerated rats. In the IND-treated rats, acid output was sig- 


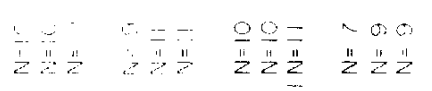

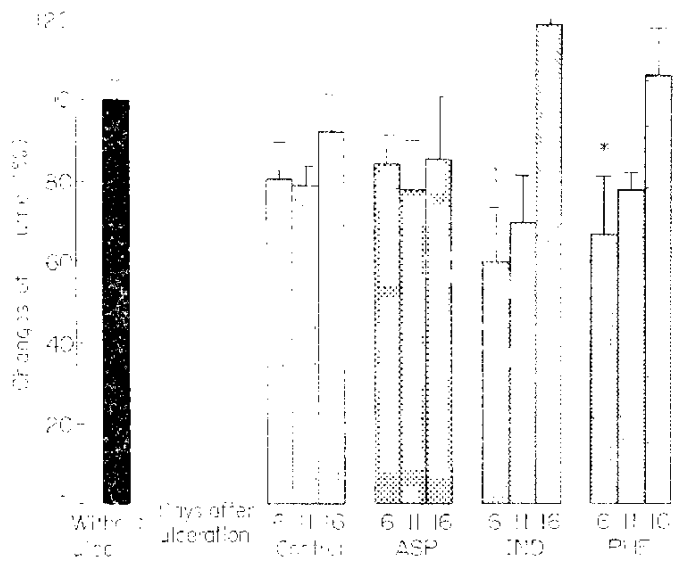

Fig. 3. Proginssive change of volumo gastic juicej in pylom-ligated ats whin acotio acid wicer

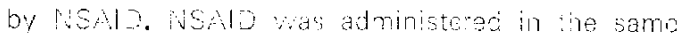
Manner as that descrbed in Fr. 1. Each valuo of the ulcoratrd somac reposents he man value compared to tast ftho no $7-$ ulcerated stomacl $(=100 \%)$. The vorical bave represent the S.E. of tho mean. The statictical id ificance of the difference is **P<0.01 or ${ }^{*}<005 \%$. the value of non-ulcerated rats on the respective day.

nificantly higher 16 days after ulceration when compared with non-ulcerated rats (Fig. 4). Sodium ionic cutput slightly decreased in all of the ulcerated groups whon comcared with non-ulcerated rats (Fig. 5). Pepsin output decreased in the ulcerated rats on either 6 days ol 11 days after ulceration. Sixteen days after ulceration, all of the ulcerated groups showed almost no influence on the output of the enzyme (Fig. 6).

\section{Progressive change of gastric emptying in} rats with ulcer: In comparison with the nonulcerated rats, there was almost no change in gastric emptying in all of the ulceratcd groups. Sixteen days after ulceration, all of the ulcerated groups, independent of the administration of NSAID, showed a slight decrease in the emptying as shown in Fig. 7.

Experiments in rats without ulcer: In the pylorus-ligated rats, only ASP-treated rats showed a significant decrease in acid output

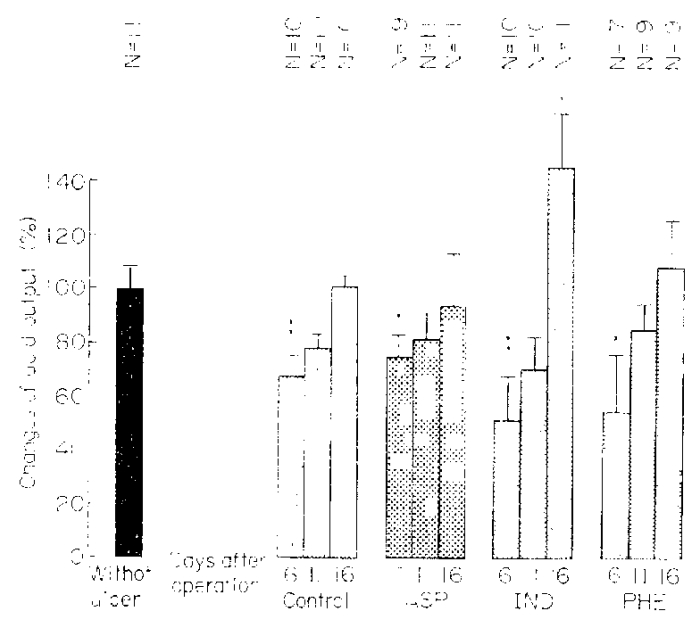

Fig. 4. Progressive change of acid output in pylorus. ligaled rats with acetic acid licer by NSAID. NSAID were administered in the same manner as that described in Fig. 1. Each value of the ulcerated stomach roprosonts the mean value compared to that of the non-ulcerats stomacin $(=100 \%)$. The vertical bers represent tie S.E. of the mean. The stasiistical significance of the difference is ** P<0.01 or ${ }^{*} P<0.05 \mathrm{ve}$. the value of non-ulcerated rats on the respecive day

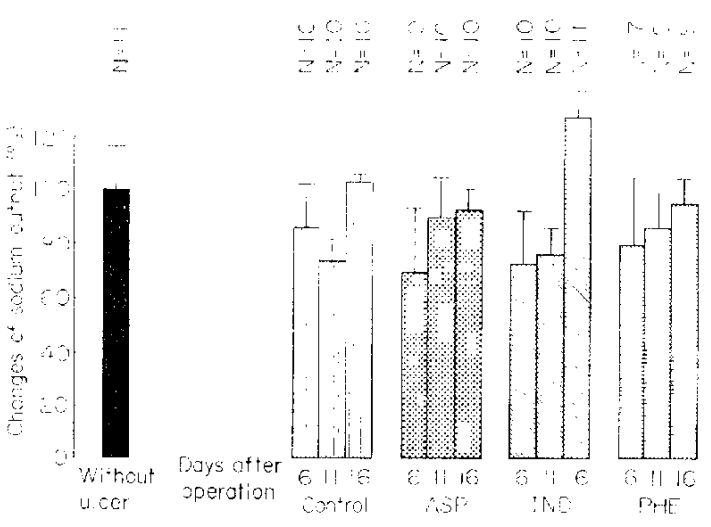

Fig. 5. Progressive change of sodium ionic output in pylorus-ligated rats with acotic acid ulcer by VSAID. NSAID wore administered in the same manrer as that described in Fig. 1. Each value of the ulceralad stomach reprosents the mean value compared to that of the non-ulcerated stomach $(=100 \%)$. The vertical bars represent the S.E. of the mean.

$(P<0.001)$ and a significant increase in socium ionic output $(P<0.001)$. Neither IND nor PHE had any effects on these outputs 
(Table 1). Gastric emptying was delayed with ASP. The other two drugs showed no effect on the emptying (Table 2). ASP showed

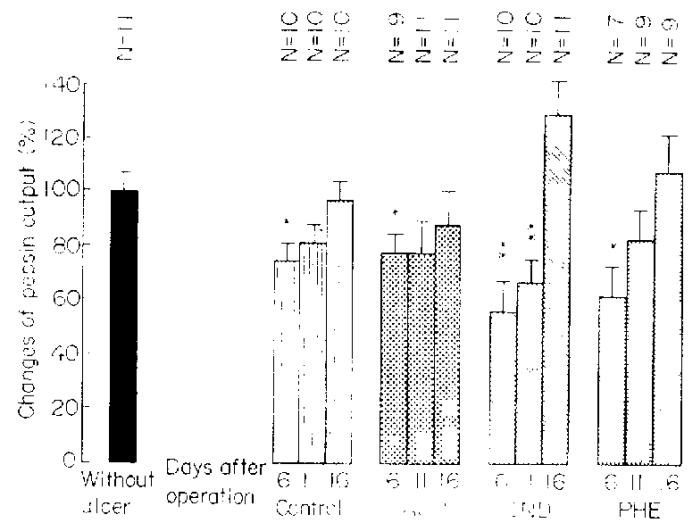

Fig. 6. Progressive change of pepsin output in pylorus-ligated rats with acotic acid ulcer by NSAID. NSAID were administered in the same manner as that cescribed in Fig. 1. Each value of the ulcoratcd stomach ropresents the mean value compared to that of the non-ulcerated stomach $(=100 \%)$. The vertical bars represent the S.E. of the mean. The statistical significance of the difference is ** $P<0.01$ or ${ }^{*} P 0.05$ vs. value of non-ulcerated rats on the respoctive day. almost no effect on the gastric contraction measured with a force transducer. The increase of the contraction was observed in rats treated with either IND or PHE. The rate of induction of the augmentation of the contraction was $58 \%$ or $33 \%$ in the rats

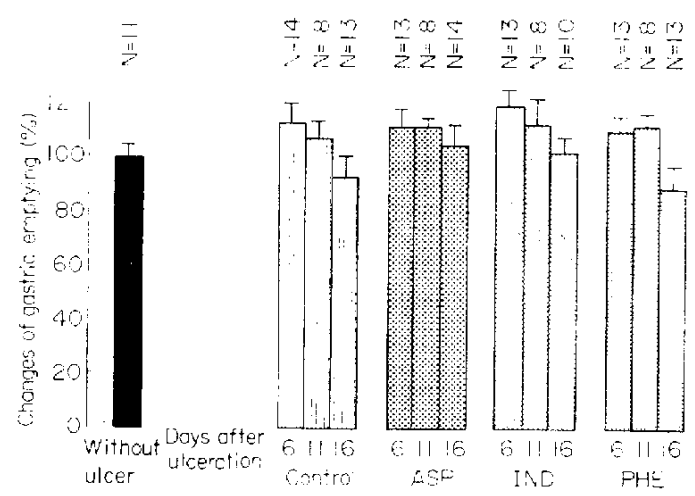

Fig. 7. Progressive change of gastric emptymg in rats with acetic acid ulcer by NSAID. NSAID was administered in the same mamer as that described in Fig. 1. Each value of ulcerated rat represonts the mean value compared with that of non-ulcerated rat $(=100 \%)$. The vertical bars represent the S.E. of tho moan.

Table 1. Effects of NSAID on gastric secretion in pylorus-ligated rats without ulcer

\begin{tabular}{|c|c|c|c|c|c|}
\hline \multirow{3}{*}{ Treatmeni } & \multirow{3}{*}{$\begin{array}{l}\text { No. of } \\
\text { rats }\end{array}$} & \multicolumn{4}{|c|}{ Analysis of gastric juice } \\
\hline & & Volume (mi) & $\begin{array}{l}\text { Acid output } \\
(\because \mathrm{Eq} / \mathrm{hr})\end{array}$ & $\begin{array}{l}\text { Sodium output } \\
(" \text { Ea/hr) }\end{array}$ & $\begin{array}{l}\text { Pepsin output } \\
(\mathrm{mg} / \mathrm{h})\end{array}$ \\
\hline & & Mean $\pm S . E$ & Mean土S.E. & Meants.E. & Mean=S.E. \\
\hline Control $(0.3 \% \mathrm{CMC})$ & 10 & $6.9 \pm 0.4$ & $111.1 \pm 4.5$ & $30.4=2.2$ & $14.8 \pm 0.5$ \\
\hline$\triangle S F^{\prime}$ & 9 & $6.5 \pm 0.4$ & $80.8 \pm 6.0^{* * *}$ & $66.8 \pm 8.0^{* * *}$ & $17.3 \pm 1.2$ \\
\hline IND & 10 & 7.4 .0 .4 & $126.7 \pm 8.0$ & $29.0-2.8$ & $16.1 \pm 0.9$ \\
\hline PHE & 8 & $7.0 \perp 0.3$ & 111.816 .3 & $30.3 \pm 2.2$ & $15.2+0.7$ \\
\hline
\end{tabular}

**p<0.001 vs. Control.

Table 2. Effects of NSADD oir gastric emplying of Evan's blue solution in rats without ulcer

\begin{tabular}{lccc} 
Treatmont & $\begin{array}{c}\text { No. of } \\
\text { rats }\end{array}$ & $\begin{array}{c}\text { Gastric emptyinglate }(\%) \\
\text { MeantS.E. }\end{array}$ & intibition rate $(\%)$ \\
Control $(0.3 \%$ CMC) & 10 & $72.1 \pm 3.4$ & - \\
ASP & 10 & $53.7 \pm 4.1 * *$ & $2 b .5$ \\
IND & 10 & $70.1 \pm 2.26$ & 2.8 \\
PHE & 10 & $72.5 \pm 2.3$ & -0.6 \\
\hline
\end{tabular}

"po. 01 vs Control. 
treated with either PHE or IND, respectively (Fig. 8). The increase induced by PHE was continued until 60 min after administration of the drug (Fig. 9).

\section{Discussion}

It has been reported that an exacerbation of ulcer was induced by the treatment of such NSAID as ASP. IND and PHE in rats with acetic acid ulcer (1). This paper is concerned with simultaneous observation of the influences of NSAID on both the ulcer index and several functions of the stomach regarding the healing process of gastric ulcer in rats. The progressive changes of mucosal hexosamine content in the surroundings of the acetic acid ulcer and changes of the gastric secretion as well as of the gastric emptying in the healing process of the ulcer were also

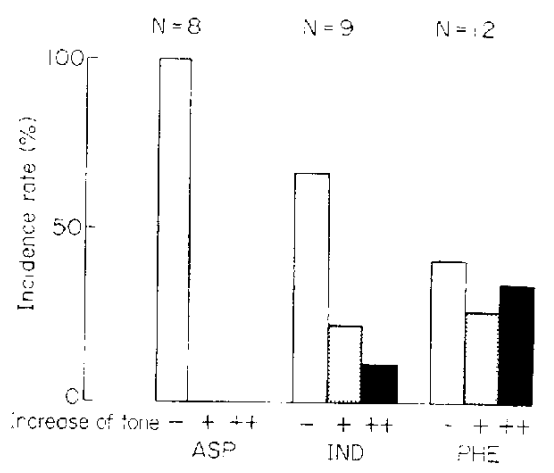

Fig. 8. Influences of NSAID on gastric contraction measured by a force transducer placed on the stomach in non-ulcerated rats. Drugs were administered in the following doses: aspirin, $200 \mathrm{mg} / \mathrm{kg}$ p.o.: indomethacin, $2 \mathrm{mg} / \mathrm{kg}$ p.o.: phenylbutazone. $100 \mathrm{mg} / \mathrm{kg} \mathrm{p.o.-}+$, and -+ show the degrees of the augmentation of the gastric contraction: - shows no effect when compared with the contraction caused by the administration of $0.3 \% \mathrm{CMC}$; - shows slight augmentation of the gastric tone: ++ shows marked augmentation of the gastric tone.
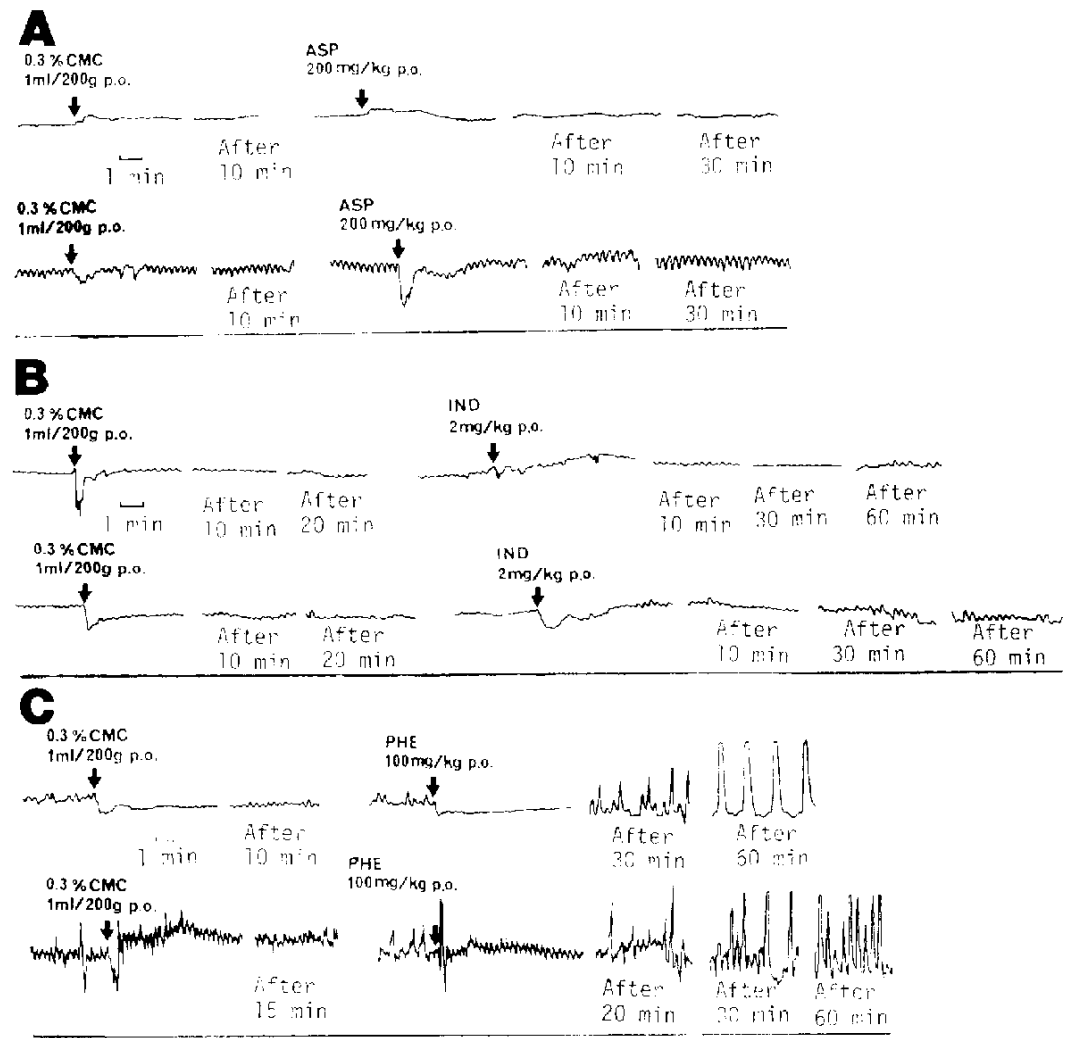

Fig. 9. Gastric motility observed in non-ulcerated rats with a force transducer placed on the stomach. A: Aspirin, $200 \mathrm{mg} / \mathrm{kg}$ p.o: B: Indomethacin, $2 \mathrm{mg} / \mathrm{kg}$ p.o.; C: Phenylbutazone, $100 \mathrm{mg} / \mathrm{kg}$ p.o. 
observed. The influences of consecutive doses of NSAID at an early stage of the ulcer for 5 days on these functions were also studied.

in a previous report, the authors found that either ASP or IND, but not PHE, caused an exacerbation in the present method (1). This paper shows that either ASP or IND produced an increase in ulcer index 16 days after ulceration when compared with 11 days after ulceration. This can be considered to be a remarkable exacerbation of the ulcer. In PHE-treated rats, an exacerbation was shown only 11 days after ulceration.

The existance of hexosamine in the gastric mucosa at high concentration is noted (13. 17. 18). We observed that the hexosamine was increased at an early stage of ulceration. This confirmed the data reported previously (13. 19). The present study shows that the increment of hexosamine was suppressed by the administration of all of the NSAID. Additionally, in rats treated with either ASP or IND, a continuous decrease of hexosamine was observed even 7 days after ulceration. It is suggested that a continuous fall in hexosamine content may be involved in the remarkable exacerbation induced by the administration of these two NSAID.

In the chronic fistula rats, the gastric secretion during the healing process of acetic acid ulcer was shown by Okabe et al. (20) That study showed that both volume and acid output in the gastric juice were immediately elevated after the ulceration as compared to non-ulcerated rats. However. in this paper, all of the ulcerated rats. independent of the administration of NSAID. showed a significant decrease in either acid output or pepsin output when compared with non-ulcerated rats. We considered that both parietal and chief cells might be damaged by the injoction of acetic acid into the submucosal layer. Neither ASP nor PHE showed any appreciable effects on either acid or pepsin output on the days studied in this investigation. IND alone showed an increase in acid output 16 days after ulceration. This effect may be concerned with the increase of the volume of gastrc juice.

The tendency for the sodium ionic output to decrease was observed in all of the ulcerated rats when compared with nonulcerated rats. In ulcerated rats, almost no effect on the sodium ionic output was shown in NSAID-treated groups when compared with the control group. It is suggested that the exacerbation induced by NSAID is not due to the back diffusion of hydrogen ion into the mucosa.

Almost no effect on the progressive change of gastric emptying in ulcerated rats was shown by NSAID from day 7 to day 17 of uiceration. Dragstedt et al. suggested that the hypersecretion induced by the gastric stasis might be causal to the pathogenesis and chronicity of the ulcer (21), while other authors reported that in gastric ulcer patients. there was no delay in gastric emptying (22. 23). Our data did not show a delayed emptying in the rats treated with NSAID during the healing process of the ulcer. From our data, the inhibition of the gastric emptying cannot be regarded as a cause of exacerbation of ulcer induced by NSAID. In non-ulcerated rats, only ASP showed a delay of gastric emptying. The inhibition induced by ASP was due to the low pH of the suspended solution of the drug. Either PHE or IND showed an augmentation of the gastric contraction. Though the effect was of short duration, it may be one of the pathogenic factors involved in the exacerbation induced by these NSAID.

In conclusion. we have confirmed that the exacerbation of ulcer was induced by NSAID. ASP or IND, especially, effected a remarkable exacerbation of the ulcer. It was found that a suppression of the increase of mucosal hexosamine and a continuous decrease of hexosamine were the causes of the remarkable 
exacerbation induced by either ASP or IND. A hypersecretion, a back diffusion of hydrogen ion and/or a delay of gastric emptying are not the pathogenetic causes of the ulcor exacerbation induced by NSAID.

\section{References}

1) Tanaka, H., Shuto, K. and Marumo, H.: Effoc: of $\mathrm{N}$-acetyl-L-glutamine aluminum compiex (KW-110), an aiti-ulcer agent, on the ronsteroida! anti-infiammatory drug-induced oxacerbation of gastric ulcer in rats. Japar. J. Pharmacol. 32, 307-314 (1982)

2) Miller, T.A. and Jacobson, E.D.: Gastrom oslinal cytoprotection by prostagiandir. Gut $20.75-87$ (1979)

3) Daniel, E.E.: The effects of diugs on the gastrointestinal tract. in Gastroomierology. Edited by Bogoch. A., p. 119-120 McGrawHill Book Co., Now York (1973)

4) Menguy, R.: Gastric mucosa! inury from common drugs. Posigrad. Med. J. 63, 82-86 (1978)

5) Wilhelmi, G and Menassé-Gdynia, R.: Gastric mucosal damage rduced by non-steroidal anti-inflammatory agonts in rats il different ages. Pharmacolyy 8, 32i-328(1972)

6) Yamagata, S., Ishimori, A and Ogawa, N.: Phase III study o: $N$-acsty - L.-glutamine alum:num complex (KW-110). J. Adult Dis. 4. $894-$ 906 (1974) (in Japanese)

7) Tanaka, H., Shuto, K., Ishii, S., Orima, H. and Takahira, $H$.: Antiulcerogenic actions and other pharmacological properties of $\mathrm{N}$-acetyl-Lglutamine aluminum comolex (KW-110). Folia Phamacol Japon. 68, 602-617 (1972) (Abs. in Englisin)

8) Tanaka, H., Shuto, K. and Marumo, H.: Effect of $\mathrm{N}$-aceivl L-glutamine aluminum complex ( $\mathrm{KW}$ 110) on experimental duodena! ulcer in rats. Pharmacomotrics 20, 185-193 (1980) (Abs. in English)

9) Takagi, K., Takeuchi, K., Nakamura, K., Morita, A. and Okabe, S.: Effects of arti-ulcer agent. $\mathrm{N}$-acetyl-L-glutamine aluminum complox (KW 110), on the duodenal ulcer modes in the iai. Japan. J. Pharracol. 24, 357-361 (1974)

10) Harada, M. and Yano, S.: Inhibitory effect of $N$-acotyl-L-glutamine atuminum complex (KW110) and rolated compouncs on gastric erosion and motiiity in strossed anirals. Phar- macometrics $8,1-6(1974)$

11) Tanaka, H., Nagashima, Z. and Takahira, H.: Study of $\mathrm{N}$-acetyl-L-glutamine aluminum complex (KW-110) on experimental chronic gastric ulcer. Pharmacometrics 7, 1035-1045 (1973) (Abs. in Englisin)

12) Takagi, K., Okabe, S. and Saziki, R.: A new methou $f(j$ the production of chronic gastric ulcer in rats and the effect of several drugs on its healing sapar. J Pharmacol. 19, 418-426 (:969)

13) Tanaka, H., Kojima, $T$, and Marumo, $H$.: Effect of $N$-acetyl-L-glutamine aluminum complex (KW-110) on hexosamine content in gastric mucosa. Pharmacometrics 9, 519-522 (1975) (Abs. in English)

14) Masamune, $H$. and Yoshizawa, Z.: Biochemica studies on carbohydrate. Tohoku J. Exp. Med. 65. 169-176 (1975)

15) Anson, M.L.: The estimation of pepsin, trypsin papain and cathepsin with hemoglobin. J. Gen. Prysiol. 22, 79-89 (1938)

16) Bobalik, G.R., Kleszynski, R.R., Aldred, J.P. and Bastian, J.W.: Differential effects of salmon porcine, and human calcitonin on gastric secretion and gastric emptying in rats. Proc. Soc. Exp. Biol. Med. 147, 284-288 (1974)

17) Robert, A., Bayer, R.B. and Nezamis, J.E.: Gastric mucus content during development of ulcors in fasting rats. Gastroenterology 45, 740751 (1963)

18) Moriga, M., Aono, M., Murakami, M. and Uchino, H.: The role of gastric mucosal hexosamine in aspirin-induced ulcers. Gastroenterol. Japon. 15, i-6 (1980)

19) Suzuki, $Y$., to, $Y$. and Sudo, $Y$.: Changes in connective tissue components in ulcer tissue during the healing process of acetic acid ulcer in rats. Japan. J. Phammacol. 29, 821-828 (1979)

20) Okabe, S. and Pfeiffer, C.J.: Chronicity of acetic acid ulcer in the rat stomach. Dig. Dis. Sci. 17. 619-629(1972)

21) Dragstedt, L.R.: A concept of the etiology of gastric and duodenal ulcer. Am. J. Roentgenol. $75,219-229$ (1956)

22) Griffith, G.H., Owen, G.M., Campbell, P.H. and Shields, R.: Gastric emptying in health and in gastroduodenal disease. Gastroonterology 54 , 1-7. (1968)

23) Wormsley, K.G.: Response lo duodenal acidification in man. W. Effect on gastric emptying. Scand. J. Gastioenterol. 7, 631-637 (1972) 